\title{
Foreword
}

\section{Günther Schmid}

The reasons to look for new institutional arrangements to cope with structural change are straightforward. Unemployment in most post-industrial societies has risen to levels unprecedented in postwar history. In countries that face this phenomenon, rising levels of unemployment have led to persistent long-term unemployment. The economic and social problems related to this development are clear: the longer the exclusion from gainful employment, the higher the risk of being also excluded from full participation in social and political life; this holds especially true for women and for young people with low skills. This threat to social integration may even undermine the trust in the basic institutions of our democratic societies. The common underlying assumption of this series of publications is that a return to full employment in the traditional sense is highly unlikely or only at unacceptable social costs. If some countries succeeded in recent years in reaching levels of unemployment like those in the 1960s, it was at the cost of either high income differentials and increasing numbers of working poor or many precarious employment relationships, especially for women, and more or less involuntary massive early retirement for many older workers. The objective of this project, therefore, is the discovery of alternatives to such ill-conceived responses to 'globalization' and 'individualization' which in different ways can generate forms of social exclusion.

It is not only structural unemployment that is of concern, although this is the most visible change. More importantly, the underlying forces of balancing supply and demand on the labour market seem to be quite different from those in the past. The aim of our common effort was, therefore, also to understand these new dynamics and to ask which institutional arrangements would be able to prevent or to alleviate the high flows into unemployment and to mitigate the concomitant adverse selection mechanisms during the subsequent difficult processes of reintegration, which often result in the unemployed also becoming victims of social exclusion. Social exclusion is the counterpart of social integration which erodes the 'cement of societies'. Social integration in modern societies, thereby, means not just having a permanent job and being protected by social rights such as unemployment benefits. It also means having the perspective of evolutionary job 
careers, having access to means and ends that ensure employability by lifelong learning or flexible work arrangements and being able to participate fully in all relevant areas of social life. The risk of unemployment is always a risk of reducing substantially the freedom of choice for a significant minority of people concerned, as well as the range of social participation.

The project was subdivided into three modules around the following topics: social integration through working time transitions (I), social integration through training and human capital investment (II), and social integration through active labour market policy (III); outside the formal contractual support, a fourth module was set up to work on a larger theoretical and empirical framework of employment systems (IV). The common underlying argument of the four modules is based on the concept of transitional labour markets. Transitional labour markets (TLM), as an analytical concept, refer to the observation that the borderlines between gainful employment and other productive activities are becoming increasingly blurred. The 'standard labour contract' is eroding but we do not know yet which new standards will develop. People transit more and more between different employment statuses, for instance between different working-time regimes, between unemployment and employment, between education or training and employment, between unpaid family work and gainful labour market work, and between work and retirement. Thus, as an analytical concept, TLM emphasize the dynamics of labour markets, which means focusing the analysis on flows rather than purely on stocks, and applying methodologies that find out and explain patterns in the many transitions during the life cycles of individuals or groups in different societies.

Some of these transitions are critical in the sense that they may lead to downward spirals of careers (exclusionary transitions), ending in recurrent unemployment or (finally) in long-term unemployment, poverty, discouraged inactivity or violent protest. We identified five major critical transitions during a life cycle: (1) the transition from school to work, (2) the transition from part-time to full-time work or vice versa, (3) the transition between family work and labour market work, (4) the transition between employment and unemployment, and (5) the transition to retirement. As a normative concept, TLM envisage new kinds of institutional arrangements to prevent those transitions from becoming gates to social exclusion and to transform them into gates for a wider range of opportunities (maintenance transitions). 'Making transitions pay' requires institutions that realize in one way or another the following principles: work organizations which enable people to combine wages or salaries with other income sources such as transfers, equity shares or savings; entitlements or social rights which allow choices to be made between different employment statuses according to 
shifting preferences and circumstances during the life cycle; and policy provisions which support multiple use of insurance funds, especially the use of income (unemployment) insurance for financing measures that enhance employability.

The following research institutions were involved in the joint venture to search for solutions to these problems: Economic and Social Research Institute (ESRI), Dublin; Hugo Sinzheimer Institute at the University of Amsterdam; Economic Faculty of the Universidad de Alcalá de Henares, Madrid; Institute for Employment Studies (IES), University of Sussex, Brighton; Manchester School of Management (UMIST), Manchester; Netherlands Economic Institute (NEI), Rotterdam; The Centre for European Labour Market Studies (CELMS), Gothenburg, in cooperation with the University of Växjö; Modélisations Appliquées, Trajectoires Institutionnelles et Stratégies SocioEconomiques) (MATISSE), Centre National de la Recherche Scientifique (CNRS) Université Paris 1; Sociological Faculty at Tilburg University; and, as coordinating institution, the Labour Market Policy and Employment Research Unit at the Social Science Research Centre Berlin (WZB). 